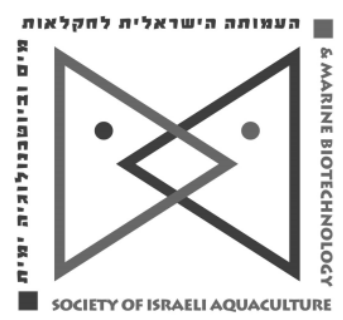

The IJA appears exclusively as a peer-reviewed on-line open-access journal at http://www.siamb.org.il. To read papers free of charge, please register online at registration form.

Sale of $I J A$ papers is strictly forbidden.

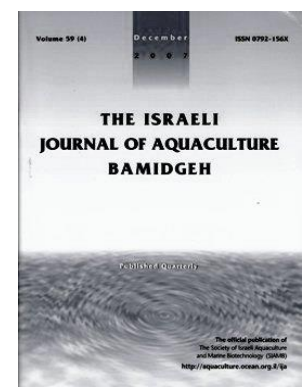

\title{
Effect of Extender Compositions, Glycerol Levels, and Thawing Rates on Motility and Fertility of Cryopreserved Wild African Catfish (Clarias gariepinus) Sperm
}

\author{
Yusuf Bozkurt ${ }^{1 *}$, İker Yavaş ${ }^{2}$ \\ ${ }^{1}$ Iskenderun Technical University, Faculty of Marine Sciences and \\ Technology, Department of Aquaculture, Iskenderun, Hatay, Turkey \\ ${ }^{2}$ Mustafa Kemal University, Faculty of Veterinary Medicine, Department of \\ Reproduction and Artificial Insemination, Antakya, Hatay, Turkey
}

Keywords: African catfish; Clarias gariepinus; sperm; cryopreservation; glycerol; fertilization

\begin{abstract}
The aim of this study was to determine the effect of different extenders, glycerol levels, and thawing rates on post-thaw sperm motility and fertilization ability of cryopreserved African catfish (Clarias gariepinus) sperm. Having determined the main spermatological properties (volume, motility, motility duration, spermatozoa concentration and $\mathrm{pH}$ ), the pooled ejaculates were diluted with 3 different extenders containing different glycerol levels (5, 10 and $15 \%$ ) respectively. Dilution ratio was $1: 10$ and the diluted sperm was packaged in $0.25 \mathrm{ml}$ straws and left for 10 min equilibration at $4^{\circ} \mathrm{C}$. Following equilibration, the straws were exposed to liquid nitrogen vapor for $10 \mathrm{~min}$ and plunged into liquid nitrogen $\left(-196^{\circ} \mathrm{C}\right)$, and then exposed to different thawing rates $\left(30^{\circ} \mathrm{C} / 20 \mathrm{~s}\right.$ and $\left.40^{\circ} \mathrm{C} / 20 \mathrm{~s}\right)$ to determine sperm motility and post-thaw motility duration. The highest post-thaw sperm motility, motility duration, and fertilization rate was $85 \%, 81 \mathrm{~s}$, and $95 \%$ respectively when sperm was frozen with the extender (ACSE 3 ) containing $15 \%$ glycerol $(p<0.05)$. The protocol reported in this study can be successfully used for cryopreservation of African catfish sperm.
\end{abstract}

\footnotetext{
* Corresponding author. email: yusuf.bozkurt@iste.edu.tr
} 


\section{Introduction}

African catfish (Clarias gariepinus) is one of the most important African benthopelagic fish species cultured in South East Asia, Africa, and Europe (Fishbase, 2016). It has also been considered one of the most suitable species for aquaculture. The availability of gametes throughout the year is an important factor to ensure a continuous supply of fish. In captivity, African catfish gametogenesis is continuous once sexual maturity is reached (Omitogun et al., 2012). At present, it is necessary to kill male brood fish or surgically remove part of their testes to obtain spermatozoa. Thus, storing spermatozoa via cryopreservation can significantly improve the reproductive potential of this species.

Cryopreservation provides many benefits such as conservation of genetic diversity, selective breeding, hybridization, and maintaining continuous and stable supply of gametes for hatchery seed production or laboratory experimentation (Lubzens et al., 1997). In addition, cryopreserved sperm can also benefit commercial aquaculture by allowing fertilization of spawn when males are not available. Development of cryopreservation for sperm of Clarias species can aid the recovery of threatened and endangered species as well as genetic selection and maintenance of selected stock lines.

Research on sperm cryopreservation in African catfish is limited regarding the use of extenders in combination with various cryoprotectants and freezing methods (Rurangwa et al., 2004). Thus, standardization and simplification of cryopreservation procedures for African catfish sperm is needed. Before freezing sperm, evaluation of different extenders, cryoprotectants, cooling and thawing rates are needed to obtain optimum cryopreservation protocols (Yavas and Bozkurt, 2011; Rurangwa et al., 2004). In addition, evaluation of the fertilizing capacity of frozen and thawed sperm is necessary to assess cryopreservation success.

The main purpose of this research was to investigate the effect of different ionic extenders, glycerol concentrations and thawing rates on post-thaw sperm motility and fertilization ability of frozen-thawed African catfish sperm.

\section{Materials and Methods}

Broodstock management. Mature wild African catfish were captured from Golbasi lake in Hatay (Turkey) and maintained in brackish-water ponds (salinity ranging from $1 \%$ o to $5 \%$ o). Sexually mature broodfish were kept separately in these shaded ponds supplied with continuously $(2.5 \mathrm{~L} / \mathrm{min})$ well-aerated water $\left(24^{\circ} \mathrm{C}, 10 \mathrm{mg} \mathrm{O} / \mathrm{L}\right)$. Broodfish were fed commercial dry feeds twice a day ad libitum and monitored daily.

Gamete collection. Before each injection and gamete collection, the broodstock were anesthetized in clove oil water bath $10 \mathrm{ml} / \mathrm{L}$ (Gabriel et al., 2011). Spermiation and ovulation were induced with an intraperitoneally injected $\mathrm{GnRH}$ analogue, Ovopel, which is obtainable as pellets weighing approximately $25 \mathrm{mg}$. Each pellet contains $18-20 \mu \mathrm{g}$ [D-Ala6, Pro9] NEt-mGnRH and 8-10 mg dopamine D2 receptor antagonist (metoclopramide) (Horvath et al., 1997). The ovopel pellets were pulverized using a mortar and dissolved in $0.7 \% \mathrm{NaCl}$ solution.

For sperm collection, 15 males $(1424.6 \pm 28.2 \mathrm{~g} ; 52.4 \pm 2.5 \mathrm{~cm})$ were injected with one pellet (per kg body weight). The injected males were kept separately in $20 \mathrm{~L}$ plastic tanks. After $24 \mathrm{~h}$, testes were removed by dissection and perforated with a needle. Sperm was gently squeezed out and collected in dry tubes. The incisions were sutured by pulling the two sides together and stitching tightly with resorbable thread. The thread was knotted after each stitch. The male broodfish were disinfected with $\mathrm{KMnO}_{4}$ (potassium tetraoxomanganate) at $1000 \mathrm{mg} / \mathrm{L}$ and returned to separate holder tanks as described by Adebayo et al., (2012). These males were starved for 1 week for proper healing of the incisions.

For egg collection, five females $(1554.2 \pm 46.5 \mathrm{~g} ; 48.6 \pm 4.6 \mathrm{~cm})$ were injected with the contents of 1.5 pellet (per kg body weight) ovopel (Interfish, Hungary) at $24^{\circ} \mathrm{C}$ water temperature. For the first injection, 0.5 pellet (per kg body weight) was applied $12 \mathrm{~h}$ before and one pellet (per $\mathrm{kg}$ body weight) was given as second injection (Brzuska, 2001). The abdomens of the females and urogenital papillas were dried before stripping. The eggs from each female were stripped into a dry metal bowl. Care was taken to avoid 
contamination with urine, mucus, feces, or water. Eggs were checked visually and those with homogenous shape, color, and size were used in the fertilization experiments.

Evaluation of sperm quality. Motility measurements were performed within $10 \mathrm{~s}$. following sperm activation. Sperm cells were activated by mixing $1 \mu \mathrm{l}$ of sperm with $20 \mu \mathrm{l}$ activation solution $(0.3 \% \mathrm{NaCl})$ on a glass slide and spermatozoa motility was determined using a phase contrast microscope (Olympus, Japan) with 400x magnification. Spermatozoa motility was examined by counting and calculating percentages of forward moving sperm cells. (Vuthiphandchai and Zohar, 1999). Spermatozoa motility was assessed in three replicates. Sperm cells that vibrated but did not move were considered as non-motile. For cryopreservation experiments, sperm samples showing below $80 \%$ motility were discarded. Duration of sperm motility was determined using a sensitive chronometer (sensitivity: 1/100s) to record the length of time until all spermatozoa ceased moving following addition of the activation solution to the sperm samples.

Spermatozoa concentration was determined by the hemacytometric method. Semen was diluted at ratio of 1:1000 with Hayem solution $\left(5 \mathrm{~g} \mathrm{Na}_{2} \mathrm{SO}_{4}, 1 \mathrm{~g} \mathrm{NaCl}, 0.5 \mathrm{~g} \mathrm{HgCl}\right.$, $200 \mathrm{~mL}$ bidistilled water) and $10 \mu \mathrm{l}$ of the dilution was counted on Thoma hemocytometer slides (depth $0.1 \mathrm{~mm}$ ). These slides were kept in a moist atmosphere for at least $10 \mathrm{~min}$ before cell counting. Mean spermatozoa count was calculated from three replicate samples for each fish at magnification of $400 \mathrm{x}$ and expressed as $\times 10^{9}$ spermatozoa $/ \mathrm{ml}$. Sperm $\mathrm{pH}$ was measured with a portable pH meter (Hanna, USA) within $30 \mathrm{~min}$ of sampling.

Cryopreservation of sperm. Collected sperm from 15 males showing $>80 \%$ motility was pooled into equal aliquots and chosen for cryopreservation experiments. Pooled semen was diluted at $1: 10(\mathrm{v} / \mathrm{v})$ ratio with three different extenders containing glycerol at concentrations of 5,10 and $15 \%$ separately. Following dilution, semen was equilibrated at $4^{\circ} \mathrm{C}$ for $10 \mathrm{~min}$. The compositions of the extenders are shown in Table 1.

Table 1: The composition of extenders used in the experiment.

\begin{tabular}{llll}
\hline Chemicals & Extenders & \multicolumn{1}{c}{ ACSE 2 } & \multicolumn{1}{c}{ ACSE 3 } \\
\cline { 2 - 4 } & ACSE 1 & $7.5 \mathrm{~g} / \mathrm{L}$ & $8 \mathrm{~g} / \mathrm{L}$ \\
$\mathrm{NaCl}$ & $4.68 \mathrm{~g} / \mathrm{L}$ & $0.2 \mathrm{~g} / \mathrm{L}$ & $0.5 \mathrm{~g} / \mathrm{L}$ \\
$\mathrm{KCl}$ & $2.98 \mathrm{~g} / \mathrm{L}$ & $0.16 \mathrm{~g} / \mathrm{L}$ & - \\
$\mathrm{CaCl}$ & $0.11 \mathrm{~g} / \mathrm{L}$ & - & - \\
Tris- $\mathrm{HCl}$ & $3.15 \mathrm{~g} / \mathrm{L}$ & - & $15 \mathrm{~g} / \mathrm{L}$ \\
$\mathrm{Glucose}$ & - & 8.3 & 6.5 \\
$\mathrm{pH}$ & 9.0 & (Kurokura et al., 1984) & (Chen et al., 1992) \\
References & (Billard and Cosson, 1992) & &
\end{tabular}

ACSE: African Catfish Sperm Extender.

The diluted semen was drawn into $0.25 \mathrm{ml}$ plastic straws (IMV, France) and sealed with polyvinyl alcohol (PVA). Straws were frozen for $10 \mathrm{~min}$ in liquid nitrogen vapor, $4 \mathrm{~cm}$ above the liquid nitrogen surface, using an insulated box with an adjustable tray. Following freezing process, the straws were plunged into liquid nitrogen $\left(-196^{\circ} \mathrm{C}\right)$ for storage. The semen was stored in a frozen state for at least two weeks. The frozen semen packaged into straws was thawed by plunging them directly into water bath at $30^{\circ} \mathrm{C}$ and $40^{\circ} \mathrm{C}$ for $20 \mathrm{~s}$. The sperm cells were activated by adding $100 \mu$ l activation solution $(0.3 \% \mathrm{NaCl})$ to determine spermatozoa motility (\%) and motility duration (s).

The thawed semen was then immediately used for fertilization experiments. Pooled eggs from five females were used to determine fertilization rates. Egg samples $(1 \mathrm{~g}=$ about 750 eggs) were inseminated in dry Petri dishes with fresh (for control) or thawed sperm immediately at spermatozoa:egg ratio of $250 \times 10^{3}: 1$. Eggs were inseminated according to the dry fertilization technique using $100 \mathrm{ml}$ fertilization solution containing 3 $\mathrm{g}$ urea and $4 \mathrm{~g} \mathrm{NaCl}$ in $1 \mathrm{~L}$ distilled water. The sperm and eggs were slightly stirred for 30 min and washed with hatchery water. Then eggs were incubated in plastic hatching vials supplied with flow-through hatchery water $\left(25 \pm 1^{\circ} \mathrm{C}, 10 \mathrm{mg} \mathrm{O} / \mathrm{L}\right)$. Oxygen was provided by continuous aeration. The fertilization rates were calculated $12 \mathrm{~h}$ after incubation by 
counting and screening the developing embryos under a stereomicroscope at $20 \mathrm{X}$ magnification. Fertilization experiments were conducted in triplicate.

Statistical analysis. Results are presented as means \pm SD. Differences between parameters were analyzed by repeated analysis of variance (ANOVA). Significant means were subjected to a multiple comparison test (Duncan) for post-hoc comparisons at a level of $a=0.05$. Analyses were carried out with SPSS 10 for Windows Statistical Software Package.

\section{Results}

Fresh semen volumes ranged from $2-9 \mathrm{ml}$ and mean volume was $6.2 \pm 1.4 \mathrm{ml}$. Motility values ranged from $85 \%$ to $95 \%$ and mean values were determined as $89.6 \pm 2.5 \%$. Mean spermatozoa movement duration (s), spermatozoa concentration $\left(\times 10^{9} / \mathrm{ml}\right)$, and $\mathrm{pH}$ values were $37.5 \pm 1.2 \mathrm{~s}, 17.8 \pm 2.4 \times 10^{9} / \mathrm{ml}$ and $7.2 \pm 1.5$ respectively.

High percentages of post-thaw motility were observed in sperm cryopreserved with $15 \%$ glycerol containing extenders. The highest mean post-thaw motility of African catfish sperm was $82.5 \pm 0.7$ when cryopreserved with the ACSE 3 extender. In general, sperm frozen with glucose based extender (ACSE 3) showed the highest post-thaw motility regardless of thawing temperature and glycerol levels (Table 2). Mean motility of fresh (control) African catfish sperm was 95.2 $18.6 \%$. Sperm cryopreserved with 5\% glycerol in ACSE 1 extender thawed at $30^{\circ} \mathrm{C}$ and $40^{\circ} \mathrm{C}$ showed the lowest mean duration of motility (29.2 \pm 0.4 and $30.6 \pm 0.9$ s, respectively).

The overall mean fertilization rate of frozen sperm was $85.0 \pm 3.3 \%$ while the best fertilization rate was $92.7 \pm 1.5 \%$ with sperm that was frozen with glucose based extender (ACSE 3) and thawed at $30^{\circ} \mathrm{C}$ for $20 \mathrm{~s}$. Mean fertilization rate of fresh (control) African catfish sperm was $98.6 \pm 2.4 \%$. Motility features and fertilization rates of cryopreserved African catfish sperm was statistically different between the experimental groups $(p<0.05)$. (Table 2).

Table 2: Effect of extenders, glycerol levels and thawing rates on post-thaw motility, motility durations and fertilization rates in cryopreserved African catfish (Clarias gariepinus) sperm.

\begin{tabular}{|c|c|c|c|c|c|c|c|}
\hline \multirow{2}{*}{ Extenders } & \multirow{2}{*}{$\begin{array}{c}\text { Glycerol } \\
\text { Levels } \\
(\%)\end{array}$} & \multicolumn{3}{|c|}{$\begin{array}{c}\text { Thawing Rates }\left({ }^{\circ} \mathrm{C} / \mathrm{s}\right) \\
\left(30^{\circ} \mathrm{C} / 20 \mathrm{~s}\right)\end{array}$} & \multicolumn{3}{|c|}{$\begin{array}{c}\text { Thawing Rates }\left({ }^{\circ} \mathrm{C} / \mathrm{s}\right) \\
\left(40^{\circ} \mathrm{C} / 20 \mathrm{~s}\right)\end{array}$} \\
\hline & & $\begin{array}{l}\text { Post-Thaw } \\
\text { Motility } \\
\text { (\%) }\end{array}$ & $\begin{array}{l}\text { Post-Thaw } \\
\text { Motility } \\
\text { Durations } \\
\text { (s) }\end{array}$ & $\begin{array}{c}\text { Fertilization } \\
\text { Rates } \\
(\%)\end{array}$ & $\begin{array}{l}\text { Post-Thaw } \\
\text { Motility } \\
(\%)\end{array}$ & $\begin{array}{l}\text { Post-Thaw } \\
\text { Motility } \\
\text { Durations } \\
\text { (s) }\end{array}$ & $\begin{array}{c}\text { Fertilization } \\
\text { Rates } \\
(\%)\end{array}$ \\
\hline ACSE 1 & $\begin{array}{r}5 \\
10 \\
15 \\
\end{array}$ & $\begin{array}{r}42.6 \pm 1.5^{a} \\
48.9 \pm 0.2^{a b} \\
57.2 \pm 0.8^{c}\end{array}$ & $\begin{array}{r}29.2 \pm 0.4^{a} \\
32.5 \pm 0.8^{a b} \\
37.9 \pm 1.2^{a b}\end{array}$ & $\begin{array}{l}40.2 \pm 4.6^{a} \\
60.8 \pm 1.4^{c} \\
70.4 \pm 0.2^{d}\end{array}$ & $\begin{array}{l}46.2 \pm 1.4^{\mathrm{a}} \\
59.7 \pm 0.6^{\mathrm{bc}} \\
54.3 \pm 1.2^{\mathrm{b}}\end{array}$ & $\begin{array}{c}30.6 \pm 0.9^{a} \\
39.8 \pm 1.6^{b} \\
35.4 \pm 0.2^{a b}\end{array}$ & $\begin{array}{l}42.3 \pm 0.2^{\mathrm{a}} \\
70.2 \pm 1.4^{\mathrm{b}} \\
72.5 \pm 1.2^{\mathrm{bc}}\end{array}$ \\
\hline ACSE 2 & $\begin{array}{r}5 \\
10 \\
15\end{array}$ & $\begin{array}{c}55.4 \pm 1.2^{\mathrm{bc}} \\
54.2 \pm 0.8^{\mathrm{bc}} \\
69.5 \pm 1.6^{\mathrm{d}}\end{array}$ & $\begin{array}{l}39.2 \pm 0.6^{\mathrm{bc}} \\
38.6 \pm 1.2^{\mathrm{b}} \\
47.2 \pm 1.9^{\mathrm{cd}}\end{array}$ & $\begin{array}{l}50.4 \pm 1.2^{b} \\
60.2 \pm 1.5^{c} \\
80.6 \pm 0.2^{e}\end{array}$ & $\begin{array}{l}62.5 \pm 1.7^{\mathrm{bcd}} \\
67.3 \pm 2.1^{\mathrm{cde}} \\
72.6 \pm 1.5^{\mathrm{e}}\end{array}$ & $\begin{array}{l}42.3 \pm 0.6^{\mathrm{bc}} \\
48.2 \pm 0.9^{\mathrm{cd}} \\
55.6 \pm 0.1^{\mathrm{de}}\end{array}$ & $\begin{array}{l}70.4 \pm 1.5^{b} \\
80.2 \pm 0.6^{c} \\
80.6 \pm 1.4^{c}\end{array}$ \\
\hline ACSE 3 & $\begin{array}{r}5 \\
10 \\
15\end{array}$ & $\begin{array}{c}72.6 \pm 0.5^{\text {de }} \\
78.9 \pm 1.6^{\text {ef }} \\
82.5 \pm 0.7^{f}\end{array}$ & $\begin{array}{l}52.7 \pm 1.8^{d} \\
55.4 \pm 1.4^{d} \\
64.2 \pm 1.5^{e}\end{array}$ & $\begin{array}{l}88.4 \pm 1.6^{f} \\
90.2 \pm 0.4^{f} \\
92.7 \pm 1.5^{f}\end{array}$ & $\begin{array}{l}68.2 \pm 1.7^{\mathrm{de}} \\
74.5 \pm 0.6^{\mathrm{e}} \\
75.2 \pm 1.8^{\mathrm{e}}\end{array}$ & $\begin{array}{l}54.2 \pm 1.5^{\mathrm{d}} \\
63.5 \pm 1.6^{\mathrm{e}} \\
78.6 \pm 1.4^{\mathrm{f}}\end{array}$ & $\begin{array}{l}70.1 \pm 0.2^{b} \\
82.4 \pm 0.6^{d} \\
86.2 \pm 0.4^{d}\end{array}$ \\
\hline
\end{tabular}

ACSE: African Catfish Sperm Extender. Values within column followed by different superscript letters indicate significant differences $(P<0.05)$.

\section{Discussion}

Sperm cryopreservation using liquid nitrogen vapor is a commonly used biotechnological technique in aquaculture (Linhart et al., 2000). During this process, spermatozoa is subjected to drastic physical and chemical changes such as ice crystal formation, mechanical and osmotic stress, and destabilization of the plasmatic membrane (Lahnsteiner et al., 1992). 
Motility is an important characteristic to estimate quality of fresh as well as cryopreserved sperm. The present research demonstrates that utilization of the glucosebased extender (ACSE 3) containing $15 \%$ glycerol produced significantly higher postthaw motility and fertilization results. In the present study, a high positive interaction was observed between post-thaw spermatozoa motility and fertilization. This finding is consistent with results obtained with common carp (Linhart et al., 2000). To the best of our knowledge, this is the first report on utilization of glycerol as a successful cryoprotectant for African catfish sperm.

The simplified extender composition, low levels of dilution, and short holding time can increase success of the cryopreservation procedure. The success of carbohydrates can be explained by their cryoprotective effect against freezing damage as membrane stabilizers. In particular, saccharides serve as extenders in cryopreservation of fish sperm (Dabrowski and Ciereszko, 1996). In our study, better fertility results were obtained using sperm frozen in glucose-based extenders containing glycerol rather than in the ionic extenders. Glycerol is one of the most important internal permeable cryoprotectants. Success, indicated by higher fertilization rates can also be linked to the adequate penetration of glycerol through the cell membranes. This indicates that glycerol has a certain protective effect against freezing damage and also acts as a membrane stabilizer. Similar results for the motility parameters of frozen-thawed spermatozoa were reported in some experiments (Tekin et al., 2007; Bozkurt et al., 2011).

Thawing rate is critical in preserving viability of the spermatozoa. There is a lack of available data regarding thawing conditions. Generally, thawing rates should be high to avoid recrystallization (Lahnsteiner, 2000; Bozkurt et al., 2014). According to the results of the present study, higher temperatures are necessary to recover membrane stability or spermatozoa. Reducing ice crystal formation and reactivation of enzymatic activities were found to be best at higher temperatures (Lahnsteiner, 2000). In the present study, thawing of frozen sperm at $30^{\circ} \mathrm{C}$ and $40^{\circ} \mathrm{C}$ for $20 \mathrm{~s}$. positively affected spermatozoa motility. However there were significant differences in fertilization rates obtained with frozen semen that were thawed at different periods and temperatures (Adebayo et al., 2012; Omitogun et al., 2012; Muchlisin et al., 2015).

Between 8,000-80,000 fresh spermatozoa per egg are required for artificial insemination in European catfish (Siluris glanis) (Linhart et al., 2004). On the other hand, in African catfish (Clarias gariepinus) the effective fertilization dosage was indicated to be $245 \times 10^{3}$ spermatozoa per egg for fresh sperm (Steyn, 1987). In the present study, higher fertilization rates were determined regardless of whether semen was frozen or fresh with an egg:spermatozoa ratio of $1: 250.000$.

Sperm quality is generally evaluated in fertilization experiments in terms of spermatozoa motility rate and percentage of live sperm (Viveiros and Godinho, 2009; Yildiz et al., 2015). It is important to note that egg quality is a crucial factor for hatchery success and fry production. One of the main reasons is difficulty in controlling of egg quality during fertilization experiments due to separation of viable from non-viable eggs. As a result of well adaptations and response of broodfish to captive conditions and induction protocol, the obtained egg quality from five females was good in the present study.

In conclusion, this study showed that the highest mean fertilization rate for frozen semen obtained with glucose-based extender (ACSE 3) containing $15 \%$ glycerol was $92.7 \pm 1.5 \%$. According to the results, cryopreservation protocol developed in the present study was effective for the successful cryopreservation of African catfish sperm. On the other hand, further studies are needed to evaluate viability, survival, and development of larvae produced from cryopreserved African catfish sperm. The applied cryopreservation protocol in this study can also be used for the recovery of endangered species as well as maintenance of selected genetic lines of broodstock in hatcheries.

\section{Acknowledgements}

The authors would like to thank to the fishermen of the Golbasi Lake in Hatay (Turkey) for their assistance. 


\section{References}

Adebayo O.T., Fasakin E.A. and J.A. Adewumi, 2012. Reproductive performance of partial gonadectomized male African catfish, Clarias gariepinus broodstocks. Theriogenology, 77: 1050-1055.

Billard R. and M.R. Cosson, 1992. Some problems related to the assessment of sperm motility in freshwater fish. J. Exper. Zool., 261: 122-131.

Bozkurt Y., Yavas I., Ogretmen F., Sivasligil B. and F. Karaca, 2011. Effect of glycerol on fertility of cryopreserved grass carp (Ctenopharyngodon idella) sperm. Isr. J. Aquacult.-Bamidgeh, IIC:63.2011.635.

Bozkurt, Y., Yavaş, I. and C. Yildiz, 2014. Effect of different avian egg yolk types on fertilization ability of cryopreserved common carp (Cyprinus carpio) spermatozoa. Aquacult. Int., 22: 131-139.

Brzuska E., 2001. Artificial spawning of European catfish Silurus glanis L.: differences between propagation results after stimulation of ovulation with carp pituitary and ovopel. Aquacult. Res., 32: 11-19.

Chen S.L., Liu X.T., Lu D.C., Zhang L.Z., Fu C.J. and J.P. Fang, 1992. Cryopreservation of sperm of silver carp, common carp, blunt snout bream and grass carp. Acta Zool. Sin., 38: 413-424.

Dabrowski K. and A. Ciereszko, 1996. Ascorbic acid protetcts against male infertility in a teleost fish. Experientia, 52: 97-100.

Fishbase, 2016. Clarias gariepinus (Burchell, 1822) North African catfish. http://www.fishbase.se/summary/Clarias-gariepinus.html.

Gabriel U.U., Deelae S.N., Akinrotimi O.A. and 0.O. Orokotan, 2011. Haematological responses of Clarias gariepinus exposed to anaesthetics metomidate. Cont. J. Pharm. Toxicol. Res., 4 (1): 18-29.

Horvath L., Szabó T. and J. Burke, 1997. Hatchery testing of GnRH analoguecontaining pellets on ovulation in four cyprinid species. Pol. Arch. Hydrobiol., 44: 221226.

Kurokura H., Hirano R., Tomita M. and M. Iwahashi, 1984. Cryopreservation of carp sperm. Aquaculture, 37: 267-273.

Lahnsteiner F., Patzner R.A. and T. Weismann, 1992. Energy metabolism in spermatozoa of the grayling (Thymallus thymallus). In: Proceedings of the Fourth International Symposium of the Reproductive Physiology of Fish (ed. by A.P. Scott, J.P.K. Sumpter, D.E. Kime \& M.S. Rofle), p. 279. Sheffield, UK. FishSymp.

Lahnsteiner F., 2000. Semen cryopreservation in the salmonidae and in the Northern pike. Aquacult. Res., 31: 245-258.

Linhart O., Rodina M. and J. Cosson, 2000. Cryopreservation of sperm in common carp Cyprinus carpio: sperm motility and hatching success of embryos. Cryobiology, 41: $241-250$.

Linhart O., Gela D., Rodina M. and M. Kocour, 2004. Optimalization of artificial propagation in European catfish, Silurus glanis L. Aquaculture, 235: 619-632.

Lubzens E., Daube N., Pekarsky I., Magnus Y., Cohen A., Yusefovich F. and P. Feigin, 1997. Carp (Cyprinus carpio L.) spermatozoa cryobanks-strategies in research and application. Aquaculture, 155: 13-30.

Muchlisin Z.A., Nadiah W.N., Nadiya N., Fadli N., Hendri A., Khalil M. and M.N. Siti-Azizah, 2015. Exploration of natural cryoprotectants for cryopreservation of African catfish, Clarias gariepinus, Burchell 1822 (Pisces: Clariidae) spermatozoa. Czech J. Anim. Sci., 60 (1): 10-15.

Omitogun O.G., Ilori O., Olaniyan O., Amupitan P., Oresanya T., Aladele S. and W. Odofin, 2012. Cryopreservation of the sperm of the African catfish for the thriving aquaculture industry in Nigeria. In: Current Frontiers in Cryopreservation, Edited by: Katkov, I. Section IV, p.305-330, Published by InTech, ISBN: 978-953-51-0302-8, 462p.

Rurangwa E., Kimeb D.E, Olleviera F. and J.P. Nash, 2004. The measurement of sperm motility and factors affecting sperm quality in cultured fish. Aquaculture, 234 (1-4): 1-28. 
Steyn G.J., 1987. The fertilizing capacity of cryopreserved shatptooth catfish, Clarias gariepinus sperm. Aquaculture, 6: 187-193.

Tekin N., Secer S., Akcay E., Bozkurt Y. and S. Kayam, 2007. Effects of glycerol additions on post-thaw fertility of frozen rainbow trout sperm, with an emphasis on interaction between extender and cryoprotectant. J. Appl. Ichthyol., 23 (1): 60-63.

Viveiros A.T.M. and H.P. Godinho, 2009. Sperm quality and cryopreservation of Brazilian freshwater fish species: a review. Fish Physiol Biochem., 35: 137-150.

Vuthiphandchai V. and Y. Zohar, 1999. Age-related sperm quality of captive striped bass Morone saxatilis, J. World Aquacult. Soc., 30: 65-72.

Yavas I. and Y. Bozkurt, 2011. Effect of different thawing rates on motility and fertilizing capacity of cryopreserved grass carp (Ctenopharyngodon idella) sperm. Biotech Biotechnol Equip., 25 (1): 2254-2257.

Yildiz, C., Yavaş, I., Bozkurt, Y. and M. Aksoy, 2015. Effect of cholesterol-loaded cyclodextrin on cryosurvival and fertility of cryopreserved carp (Cyprinus carpio) sperm. Cryobiology, 70 (2): 190-194. 